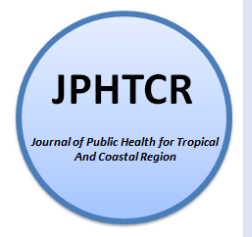

JOURNAL OF PUBLIC HEALTH FOR TROPICAL AND COASTAL REGION (JPHTCR)

Journal homepage: http:/ejournal2.undip.ac.id/index.php/jphtr/index

ISSN : 2597-4378

Research Article

\title{
Analysis of Reinforcing Factor with Involvement of Informal Sector Workers in Occupational Health Post (Pos UKK)
}

\author{
Muhammad Dyas Husnan Khair ${ }^{a}$, Ayun Sriatmi ${ }^{b}$, Bina Kurniawan ${ }^{c}$ \\ a Staff of the Center for Planning and Utilization of Human Resources, Ministry of Health, Indonesia. \\ correspondence : $\underline{\text { muhammad_dyas@yahoo.com }}$ \\ ${ }^{b}$ Lecturer in Administration and Public Health Policy Dept., Faculty of Public Health, Diponegoro University, \\ Indonesia \\ ${ }^{c}$ Lecturer in Occupational Health and Safety Dept., Faculty of Public Health, Diponegoro University, Indonesia
}

\begin{abstract}
Background: Occupational Health Post (Pos UKK) is a program aims to improve occupational health and productivity of informal sector workers in Indonesia through promotive, preventive, simple curative and rehabilitative care with the principle of Community Based Health Efforts (UKBM). The number of Pos UKK registered in Semarang City Health Office is 30 units. The results of the preliminary study illustrate different situations because there were only 6 Pos UKK. Among those, only 2 were active $(6.7 \%)$ from the registered Pos UKK. It's alleged that inactivity of Pos UKK due to low support from various parties and impacted on low sustainability of the program. This study aims to analyze the reinforcing factor with the involvement of informal sector workers in Pos UKK in Semarang City.

Methods : Quantitative study with cross sectional approach. Population were 146 workers and selected sample were 70 workers. Independent variables include co-worker support, business owner support and Community Health Centre (Puskesmas) support and dependent variable is involvement of informal sector workers in Pos UKK.

Results : Majority of informal sector workers involvement in Pos UKK were low $(51,43 \%)$. Co-worker and business owners support was good but Puskesmas support as guide was not. Statistically, co-worker support ( $\mathrm{p}=$ 0,000, OR = 30.8), business owner support $(\mathrm{p}<0.001, \mathrm{OR}=10.6)$ and Puskesmas support $(\mathrm{p}<0.001, \mathrm{OR}=13.5)$ proved to have a significant relationship.

Conclusion:This study showed that reinforcing factors have significant relationship in increasing involvement of informal sector workers in Pos UKK to ensure program sustainability. Puskesmas is expected to provide continuing assistance and socialization about the benefits of Pos UKK to informal sector workers.
\end{abstract}

Keywords : reinforcing, support, Pos UKK

\section{Background}

Cases of work-related accidents and diseases are still common in Indonesia. Throughout the year 2015 there have been 110,285 cases of work-related accidents in Indonesia which reached 1981 workers to disability (1.8\%) and 530 workers died $(0.48 \%){ }^{1}$ Group of workers who are vulnerable to work-related accidents and diseases are informal sector workers. The number of informal sector workers in 
Indonesia still dominates 68.2 million (57.61\%) compared to the formal sector which was 50.2 million $(42.9 \%) .{ }^{2}$ Thus, one of the government programs in addressing occupational health problems in the informal sector is through Occupational Health Post (Pos UKK).

Pos UKK is a program aims to improve occupational health and productivity of informal sector workers in Indonesia through promotive, preventive, simple curative and rehabilitative care with the principle of Community Based Health Efforts (UKBM). ${ }^{3}$ Based on data from the Directorate of Occupational Health and Sports, Ministry of Health Indonesia in 2017 the number of Pos UKK continues to increase from 2015-2017. In 2017 alone, there are 2931 Pos UKK in Indonesia. Central Java were province with the third highest number of Pos UKK in Indonesia in 2017, which was 232 (7.9\%). ${ }^{4}$ Meanwhile in Semarang City there were 30 Pos UKK located in 20 working areas of Puskesmas. ${ }^{5}$

Based on the preliminary survey, from 20 Puskesmas that should have Pos UKK, only 4 Puskesmas have Pos UKK with the total number 6 Pos UKK units. It shows that the number of Pos UKK in Semarang City is not as much data received from Health Department. Among those, only 2 were active $(6.7 \%)$ from the registered Pos UKK. In system approach, a program can run or work well if the input and process aspects are well managed. In the context of Pos UKK in Semarang City there was an output that has not been optimal, especially in the involvement of workers. It should be further investigated how the involvement of informal sector workers in Pos UKK.

\section{Methods}

Type of study conducted is quantitative study using cross sectional study approach.
The study took place at 6 Pos UKK in Semarang city which are KOPIN, Mina Karya, UPPKS IKA MANDIRI, Pengrajin Besi, Berkah SSV and Gunung Mas Beton . The independent variables include coworker support, business owner support and Puskesmas support as well as dependent variable is the involvement of informal sector workers in Pos UKK. The population in this study were 156 members of Pos UKK. Respondents were determined by the sample calculation using Lemeshow formula so that 70 respondents were obtained. Respondents were determined by proportional random sampling technique and fulfilled inclusion and exclusion criteria. The inclusion criteria in this study were: registered as a member of Pos UKK; location of the respondent was accessible to the researcher.

This study uses chi-square test with ordinal scale to know the value of OR (Odds Ratio). Data collected by interview using structured questionnaire instrument. Scoring technique used was Likert scale 14. Study hypothesis is there is a relationship between co-worker support, business owner support and Puskesmas support with the involvement of informal sector workers in Pos UKK.

\section{Results}

Table 1. shows the characteristics of respondents. The majority of respondents were female $(55.7 \%)$. Respondents with the lowest age was 15 years old and the highest was 51 years old with the largest percentage was in the age range $26-45$ years $(84.3 \%)$. Most of the respondents had junior high school education background (40.0\%) followed by high school (28.3\%), elementary school $(28.3 \%)$ and no formal education $(2.8 \%)$. 


\begin{tabular}{lrr}
\hline \multicolumn{1}{c}{ Characteristic } & Total & \\
\cline { 2 - 3 } Gender & F & \% \\
Male & 31 & 44.3 \\
Female & 39 & 55.7 \\
\hline Age & & \\
Late teen (17-25) & 6 & 8.6 \\
Early adulthood (26-35) & 34 & 48.6 \\
Late adulthood (36-45) & 25 & 35.7 \\
Early elderly (46-55) & 5 & 7.1 \\
\hline Education level & & \\
No formal education & 2 & 2.8 \\
Elementary school & 20 & 28.6 \\
Junior high school & 28 & 40.0 \\
Senior high school & 20 & 28.6 \\
\hline
\end{tabular}

Table 1. Characteristic of workers

Table 2 shows that workers with low involvement has low support from co-worker (89.7\%), business owner $(80.0 \%)$ and Puskesmas (77.8\%). On the contrary, informal sector workers with high involvement have better support. The findings are also supported by statistical test results of significance value on the relationship of these three variables. From the results of OR also shows that reinforcing factor plays an important role in determining the level of involvement of informal sector workers in Pos UKK.

\begin{tabular}{|c|c|c|c|c|c|c|}
\hline \multirow{3}{*}{ Variable } & \multicolumn{4}{|c|}{ Involvement of Informal Sector Worker } & \multirow{3}{*}{ p-value } & \multirow{3}{*}{$O R$} \\
\hline & \multicolumn{2}{|c|}{ Low } & \multicolumn{2}{|c|}{ High } & & \\
\hline & $\mathrm{f}$ & $\%$ & $\mathrm{f}$ & $\%$ & & \\
\hline Co-worker Support & & & & & $0.000^{*}$ & 30.8 \\
\hline Low & 26 & 89.7 & 3 & 10.3 & & \\
\hline High & 9 & 22.0 & 32 & 78.0 & & \\
\hline Business Owner Support & & & & & $0.000^{*}$ & 10.6 \\
\hline Low & 24 & 80.0 & 6 & 20.0 & & \\
\hline High & 11 & 27.5 & 29 & 72.5 & & \\
\hline Puskesmas Support & & & & & $0.000^{*}$ & 13.5 \\
\hline Low & 28 & 77.8 & 8 & 22.2 & & \\
\hline High & 7 & 20.6 & 27 & 79.4 & & \\
\hline
\end{tabular}

Table 2. Results of the analysis between co-worker, business owner and Puskesmas support with the involvement of informal sector workers in Pos UKK

\section{Discussion}

Based on the results of this study, it was evident that half of informal sector workers had low involvement in Pos UKK. During the implementation of Pos UKK, the members were already encourage others to get involved. However, there are still a few members who always follow every activity and attend on time and their 
surrounding had little support to encourage workers to participate in Pos UKK. This illustrates that in general there were still many obstacles in the involvement of informal sector workers in Pos UKK.

The implementation of Pos UKK requires a lot of resources so the effectiveness and efficiency Pos UKK must be considered. Therefore, Puskesmas need to develop capability in self and need assessment as well as in determining informal sector work group which have potential to form and develop Pos UKK. Self assessment aimed to see the ability of Puskesmas to form and maintain Pos UKK. While the need assessment aimed to see the need of workers about Pos UKK, so that Pos UKK isn't one-sided from government like of Puskesmas or health office to form and implement Pos UKK. Puskesmas can also see workers that have the potential to conduct a good community activity such as Pos UKK. Pos UKK is expected to be organized by all informal sectors workers because basically every worker has the right to occupational health and one of the efforts to get it is through Pos UKK. By doing all those activities, Puskesmas can accurately analyze their ability and also determine the appropriate target group of workers for Pos UKK.

\section{Relationship between co-worker support with involvement of informal sector workers in Pos UKK}

Co-workers are mostly supportive about Pos UKK. The result of chi-square statistic test showed a significant relationship between co-workers support with involvement of informal sector workers in Pos UKK. Social support is an exchange between two individuals or more with giving and receiving condition. According to Sarafino, there are five forms of social support, namely emotional support, rewards, instrumental, information and groups. ${ }^{6}$ In Pos UKK, cooperation and support among co-worker is needed. Without support between co-worker, the involvement of workers in the Pos UKK is low so that it may affect the sustainability of the Pos UKK. Co-worker support can be in from of a regular and continuous communication of activity, reminding to be actively involved, willingness to discuss, helping if there are any obstacles, convincing to carry out tasks and provide suggestions. Although most co-workers have supported, there are co-worker who had not reminded, willing to help and provided advice in Pos UKK. Most of them acknowledge that among workers was less caring. They are still reluctant to discuss the Pos UKK because it is considered less important and feel a lot of work to do in addition to helping the implementation of Pos UKK.

In this study, co-worker support is one of the factors that had shown to influence the involvement of workers in Pos UKK. Co-worker support is one of the social support that needed by workers to help them in Pos UKK. Johnson also stated that high social support can make individual productivity higher. With the support of coworkers, workers feel comfortable, cared for, listened to, and appreciated. ${ }^{7}$ Therefore, the need to increase support among coworkers can be done by improving coordination and communication among them in Pos UKK. Through coordination and communication, workers will understand each other's needs and activities. It is expected that co-workers care, appreciate, assist, advise, direct and provide feedback for each other in every activity in Pos UKK.

\section{Relationship between business owner support with involvement of informal sector workers in Pos UKK}

Support of business owners in Pos UKK already good. The result of chi-square statistical test shows that there was a significant relationship between business owner support with involvement of informal sector workers in Pos UKK. Leadership describes the relationship 
between the leader and the follower and how a leader directs the follower will determine how far the follower reaches the leader's goals or expectations. It was found that there was lack of support from business owners in Pos UKK. Business owner still has not provided any information related to Pos UKK. Some members of Pos UKK stated that the business owner is indifferent to Pos UKK. They also forbid them to participate in Pos UKK. Pazy stated that one of the factors that affect the job performance is the support from worker's superiors. ${ }^{8}$

Chen also stated that high support from the leader of the company could encourage employees to work better and achieve their desired goals. Through support from their surrounding environment, workers can increase the intensity of work that needs to be done. ${ }^{9}$ It is clear that low support from business owner resulted in low involvement of workers in Pos UKK. Therefore, Puskesmas need to improve coordination with business owners in order to support workers in Pos UKK. Some of the efforts that can be done is to persuade business owners to give permission to workers to get involved in Pos UKK so that workers become more viable and motivated to follow the activities of Pos UKK.

\section{Relationship between Puskesmas support with involvement of informal sector workers in Pos UKK}

This research indicates that Puskesmas is less supportive towards workers in Pos UKK. The result of chisquare statistic test showed a significant correlation between Puskesmas support with informal sector worker involvement in Pos UKK. The majority of respondents agreed that Puskesmas have not provided incentives in the Pos UKK. Members of Pos UKK consider that the grants provided can help them. In addition to not providing assistance in the form of funds, Puskesmas also not doing enough effort in facilitated
Pos UKK. Puskesmas has not helped to prepare the needs of facilities and infrastructure for the operational needs of Pos UKK. Members of Pos UKK stated that Puskesmas have not provided clear information related to Pos UKK. Coordination and communication between internal Puskesmas with workers and business owners are also considered not optimal so Pos UKK has not run well.

According to Cohen and Mckay in Sarafino, one of the form of support is "real support". This support should be given appropriately in order to be effective, otherwise individuals who are provided with too much support will be less appreciative or even feel indebted resulting in stress. ${ }^{6}$ Akbar in his research explained that the support of health workers from the Puskesmas is very important and can not be ignored like to encourage cadres to be active. ${ }^{10}$ Members of Pos UKK who are volunteers like the Posyandu cadres, need to receive adequate incentives. Without adequate incentives, the effectiveness and sustainability of long-term programs are threatened. ${ }^{11}$

Incentives may be in the form of money, goods, recreational entertainment and others. The process of establishing Pos UKK is not an instant where it requires continuous active participation by members to carry out Pos UKK activities. Members of Pos UKK are also informal sector workers who have their own workload and volunteered to join Pos UKK activities. Therefore, appropriate incentives should be provided. This is also reinforced by the results of research conducted by Simanjuntak which proves that incentives can stimulate cadre performance. ${ }^{12}$

The internal organizational aspects in Puskesmas related to Pos UKK program should be organized clearly where this aspect is also important and can affect the future of Pos UKK This organizing involves tasks given and the person in charge in Pos UKK program. In inactive 
Pos UKK, Puskesmas does not have a clear organization where there is no structure or person in charge and details of tasks related to Pos UKK program. Thus, it is necessary to organize in implementing Pos UKK program. Puskesmas can create substructures under the field of Health Promotion or Occupational Health in Pos UKK program. Details of tasks are also developed for these sub-structures in operational guidelines that refer to existing Pos UKK rules and guidelines. Pos UKK activities can also be integrated between Puskesmas programs such as environmental health, maternal and child health and family planning, nutrition and others in order to make Puskesmas easier to make public health efforts optimum.

In addition, Puskesmas should collaborate with Health Office to provide support for Pos UKK especially inactive Pos UKK. This can be done through revitalization of Pos UKK where this revitalization aims to improve the function and performance of Pos UKK. Revitalization of Pos UKK can adopt Posyandu revitalization concept. Pos UKK revitalization is expected to improve the quality of the skills and skills of the members of Pos UKK, improve the management, improve the facilities and infrastructure, increase partnership and integration of workers and improve the assistance and quality of Pos UKK training. Revitalization of Pos UKK also can be done by continuous guidance and socialization about benefit of Pos UKK to informal sector workers and other parties who are involved.

\section{Conclusion}

Access to occupational health in Indonesia especially in informal sector workers should receive adequate and appropriate attention. One of them is through Pos UKK program. Unfortunately, many of the Pos UKK in Semarang City were not active. It was proven by this study that workers had low involvement in Pos
$U K K$. Reinforcing factor has a significant relationship with involvement of informal sector workers in Pos UKK. Reinforcing factors include support of co-workers, business owners and Puskesmas given to workers in various aspects such as facility, emotional, financial, policy and other form of support. Good reinforcing factors will increase worker involvement to ensure program sustainability.

It is recommended for business owners to grant workers permission to participate in Pos UKK. Puskesmas with the Health Office should also provides ongoing assistance and socialization on the benefits of Pos UKK to informal sector workers. In addition, all inactive Pos UKK should be immediately revitalize.

\section{Acknowledgement}

We would like to thank all workers who took part in the study and gratefully acknowledge Faculty of Public Health Diponegoro University. Our thanks are also extended to Semarang City Health Office and Puskesmas for helping this study.

\section{Conflict of Interest}

There is no conflict of interest.

\section{References}

1. Social Security Administrative Body for Employment Indonesia. Resume of Program Management Report (Audited) 2015. Jakarta; 2015

2. Central Bureau Statistics Indonesia. National Labor Data in 2017.

3. Directorate of Occupational Health and Sports. Guideline of Implementation in Pos UKK for Pos UKK Cadres. Jakarta: MOH Indonesia; 2013.

4. Directorate of Occupational Health and Sports. Data on Recapitulation of Worker's Monthly Working Report in 2016. Jakarta: $\mathrm{MOH}$ Indonesia; 2017

5. Semarang City Health Office. Data on Pos UKK at Semarang City in 2017.

6. Sarafino E. Health Psychology. England: John Willey \& Sons; 2006. 
7. Johnson D., Johnson F. Joining Together: Group Theory and Group Skill (7th Ed.). New Jersey: Boston Allyn and Bacon; 2000.

8. Pazy A. Pay Contingency And The Effects of Perceived Organizational and Supervisor Support on Performance and Commitment. Work Pap Res. 2006.

9. Chen, Yuen, Li. Examining The Effect of Organizational Culture and Leadership behaviorsmen Organizational Commitment, Job Satisfaction, and Job Performance at Small and Middle Sized Firms of Taiwan. J Am Acad Bussiness. 2001.

10. Akbar MA, Kandarina BI, Gunawan IMA. Studi Ketidakaktifan Kader Posyandu di Wilayah Kerja Puskesmas Paramasan, Banjar, Kalimantan Selatan. 2015.

11. World Health Organization. Scaling up, Saving Lives. Geneva: WHO; 2007.

12. Simanjuntak M. Social Demography Characteristics and Driven Factors in Improving Performance of Cadre of Integrated Services Centre (Posyandu). JWEM (Jurnal Wira Ekon Mikroskil). 2012. 